\title{
Assessment of the Municipal Solid Waste Transfer Stations Suitability in Harare, Zimbabwe
}

\author{
Trust Nhubu ${ }^{1, *}$, Edison Muzenda ${ }^{1,2}$, Mohamed Belaid $^{1}$, Charles Mbohwa ${ }^{3}$
}

${ }^{1}$ Department of Chemical Engineering Technology, University of Johannesburg, Johannesburg, 0027, South Africa

${ }^{2}$ Department of Chemical, Materials and Metallurgical Engineering, Botswana International University of Science and Technology, Palapye, 00267, Botswana

${ }^{3}$ Department of Quality and Operations Management, University of Johannesburg, Johannesburg, 0027, South Africa

\begin{tabular}{l} 
A R T I C L E I N F O \\
\hline Article history: \\
Received: 22 December, \\
Accepted: 19 February, \\
Online: 22 April, 2021 \\
\hline Keywords: \\
Municipal solid waste \\
Life cycle impacts \\
Waste transfer station \\
Integrated solid waste \\
management \\
Citizens drop off points \\
Buy back centres \\
Recycling \\
Harare \\
Zimbabwe
\end{tabular}

\section{Introduction}

This paper is a revised and extended version of a paper entitled, "Suitability of municipal solid waste transfer stations in Harare, Zimbabwe", that was presented at the 7th International Renewable and Sustainable Energy Conference (IRSEC' 19), Sofitel Agadir Royal Bay, Agadir, Morocco, November 27-30, 2019.

\footnotetext{
"Corresponding Author: Trust Nhubu, Department of Chemical Engineering Technology, University of Johannesburg, P O Box 17011, 2028, South Africa, 2094,+263777342295, nhubutrust@gmail.com
}

\begin{abstract}
A B S T R A C T
The suitability of incorporating waste transfer stations (WTS) in likely future Municipal Solid Waste Management (MSWM) systems for Harare city and neighbouring urban centres was assessed under this study. WTS will bring about location of landfills and other MSWM facilities further away from population centres, increasing recycling, reducing waste collection costs and burden on the overall MSWM budget, an increase in waste collection effectiveness and efficiency, reduction in waste collection derived greenhouse gases (GHG) emissions and other associated impacts. Life cycle Assessment (LCA) on contribution of waste collection to human health impact potential of $34 \mathrm{DALYS}$ as well as acidification, global warming and eutrophication impact potentials of 0.012, 0.065 and 0.0002 species.year respectively under all the six MSWM options were observed. Highest impacts in the species extinction impact categories was realised in the global warming impact category resultant of GHG emissions from fuel combustion during waste collection. The unavailability of land and the above factors support the incorporation of WTS in future MSWM options for Harare City and surrounding urban centres under a separation at source waste collection system to derive maximum benefits. Citizens drop off centres (CDOPs) and buy-back centres (BBCs) could also compliment the WTS leading to increased recycling. Though there is a relative sound supportive legislative, regulatory and policy framework that supports the need for waste recycling consequently supporting WTS, CDOPS and BBCs due to their recycling promotion capabilities, there is need for specific legislation, regulation and policies that supports the development and operation of such facilities that will bring interest amongst would be operators, effectiveness and efficiency resultantly reducing associated human health and environmental impacts. Further studies that determine the breakeven distance and LCA studies that specifically assess the associated environmental loads of incorporating WTS within the likely future MSWM systems are recommended.
\end{abstract}

The continued population increases together with the prevailing rapid urbanization has resulted in astronomical increase in MSW generation rendering the management of municipal solid waste (MSW) a challenging and difficult task for urban local authorities (ULAs) especially in low income countries. In [1], the authors projected annual global MSW generation to increase from $1.3 \times 10^{9}$ tons $(1.42 \mathrm{~kg} / \mathrm{capita} /$ day $)$ in 2012 to $2.2 \times 10^{9}$ tons in 2025 . This results in an evident mismatch between increased population and urbanisation rate with the necessary corresponding municipal solid waste management (MSWM) investment, infrastructure, 
equipment and expertise in the face of the MSW generation spike [2]. Significant increase in urbanization from general population increases coupled with rural to urban migration in pursuit of better life and jobs [3] has been a global phenomenon characterizing the recent past decades. In [4], the author reported global urbanization levels of $29.6 \%$ and $55.3 \%$ in 1950 and 2018 respectively, simultaneously projecting global urbanisation to increase to $68.4 \%$ by the middle of the $21^{\text {st }}$ century. Increasing urbanisation rates were reported in the 1982, 1992, 2002 and 2012 Zimbabwe national census reports [5]. The increase in the urbanisation is also confirmed by [4] which reported urbanisation levels of $32.2 \%$ in 2018 and $45.9 \%$ in 2050 for Zimbabwe as well as $40.4 \%$ in 2018 and $58.1 \%$ in 2050 for Sub Saharan Africa (SSA) implying that by mid- $21^{\text {st }}$ century, urban population in SSA would have outstripped rural population constituting over $58 \%$ of the total population. Increased population densities together with the corresponding increases in MSW generation characterise these reported increasing urbanization rates $[6,7]$. The increase in MSW generation is significantly not matched with the required corresponding expertise and infrastructural (equipment and technology) development with regards to MSW storage, collection and transportation, management, treatment and disposal.

Increased MSW generation associated challenges are realised or manifest first in the first stages of a MSWM system namely storage, collection and transportation. MSW collection figures of slightly above $40 \%$ were reported by [1] for developing nations as shown in Figure 1. MSW collection figures of below half of the MSW generated in the Zimbabwean ULAs have been reported with the collected waste disposed of at official open dumpsites whilst the over 50\% non-collected MSW generated is subjected to any of the following illegal methods namely; burning, burying, dumping in undesignated areas like road sides, vacant spaces, alleys, storm water drains. All these MSW disposal methods including the dumping of the officially collected MSW at official dumpsites pose potential and imminent human health and environmental disasters already manifesting or in the making. MSW disposal thus becomes as equally vital stage as the first stages of a MSWM system. Figure 2 provides a comparative overview of the dominant MSW disposal methods in Harare (Zimbabwe) as reported by [8] and those reported by [1] for low income countries.

In Zimbabwe, ULAs including municipalities, city and town councils, rural district councils as well as local boards are authorised entities responsible for MSWM [9] largely under centralised and conventional models inherited from the colonial error which has no clear mechanisms for cooperation between the ULAs and other stakeholders especially residents to be served by such a MSWM system who have developed a 'we dumb they collect attitude' [10]. ULAs are authorised also to engage other players for the purposes of managing waste on their behalf. MSWM was singled out by [11] amongst the enormous challenges facing ULAs within the vicinity of Harare the Capital City of Zimbabwe including Chitungwiza municipality, Epworth, Ruwa and Norton local boards largely due to the astronomical increase in MSW generation presently estimated at above 400,000 tons [12] which has not been matched with corresponding increases in capacity development with regards to financial, infrastructure (equipment and technology) and technical expertise. The population increases together with the associated increased www.astesj.com population density and the ensuing MSWM challenges from the mismatch between the population dynamics and developments in MSWM with regards to infrastructure (technology and equipment), finance and investment and technical expertise to manage the ever-increasing amount of MSW being generated evidently manifest in the form of water pollution (both surface and groundwater) together with the perennial water borne diseases outbreaks namely Cholera, Typhoid and Dysentery [13-15].

MSW collection and transportation (MSW-CT) from its sources to final disposal dumpsites in Harare city, Chitungwiza, Ruwa, Epworth and Norton consume more than the expected reported proportion on MSWM budget of between 20 to 50\% [16] and 50 to $70 \%$ [17]. Therefore, there is need to redesign future MSW-CT to possibly allow for significant cost reductions on MSW-CT cost which will result in savings on the MSWM budget with the savings possibly channeled towards other developments in other MSWM downstream processes, infrastructure and technical expertise. The incorporation of appropriately designed, sited and constructed WTS in MSWM systems is such a strategy towards bringing cost effective and savings in MSW-CT [18-21]. WTS apart from their costs abatement capabilities they could possibly bring about reduced environmental impacts of future MSWM systems that could be implemented in Harare city, Chitungwiza, Ruwa, Epworth and Norton. In [22], the authors observed that the recycling of atleast $20 \%$ of the recoverable materials contributes to significant reductions of environmental impacts (acidification, eutrophication, human health and global warming) of MSWM options that could be earmarked for future implementation in Harare city, Chitungwiza, Ruwa, Epworth and Norton. WTS have largely been reported that they can act as platforms for recycling and materials recovery hence their incorporation in future MSWM systems as platforms for recycling and materials recovery will result in reduced environmental impacts. This study therefore complements extensive literature review with LCA of the suitability of WTS for Harare city, Chitungwiza, Ruwa, Epworth and Norton considering the need to redesign and implement future sustainable MSWM systems along the integrated waste management model, the likely capacity exhaustion by 2020 of the only dumpsite for Harare (Pomona dumpsite), key national priorities and objectives under the Zimbabwe National Integrated Solid Waste Management Plan (ZNISWMP) that came into effect in July of 2014 and the Zimbabwean Government waste sector Low Emission Development Strategies (LEDS) for the Nationally Determined Contributions (NDCs) to its Paris Agreement differential obligations or responsibilities under the United Nations Framework Convention on Climate Change (UNFCCC).

\section{Waste Transfer Stations}

WTS provide linkages between MSW generation, storage, collection and transportation and final disposal (landfill or MSW processing facility) for a specific spatial scale (locality or community over a given temporal scale [23]. WTS consolidate MSW from different primary small or low volume MSW collection vehicles from MSW sources into secondary large or high volume collection vehicles to effect low MSW transportation cost by using the secondary large or high volume collection vehicles to haul MSW to distantly located waste treatment (anaerobic digestion and or a composting, incineration, pyrolysis, 
gasification, waste to energy facilities etc) and disposal sites mainly landfills. Material Recovery Facilities (MRFs) are specialised WTS where recyclables are segregated and consolidated prior to waste transportation to landfills or other MSW treatment and disposal facilities [19, 21]. Therefore WTS operating as MRFs diverts waste sent to landfills thereby bringing along with significant environmental benefits such as reduced land sizes for landfills and demand for land considering its competing interests amongst its uses.

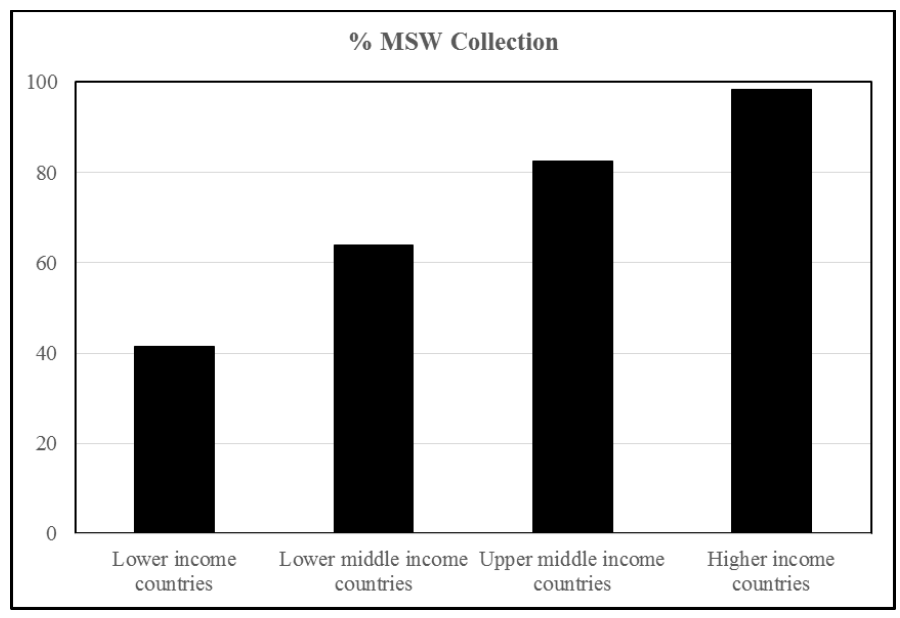

Figure 1: MSW collection according to country income levels [1]

a

MSW disposal method in Harare

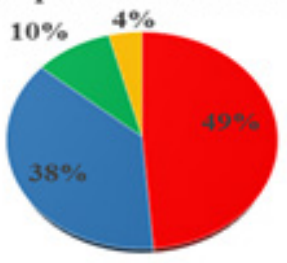

- Dumpites

- Buried and burat at source

- Regyeled

- Indiscriminately dumped at undesigated areas

b MSW disposal methods in low income country

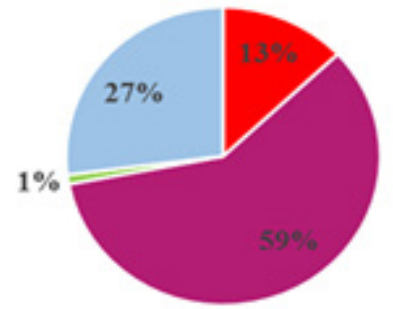

- Dumpsites - Landnals - Compost - Other

Figure 2: Dominant disposal methods in Harare (a) $[8,24]$ and low income countries (b) [1]

\subsection{Reasons for Waste Transfer Stations}

WTS bring about a number of benefits to a MSWM system including reduced transport costs, reduced pollution, easing of selecting new sites for MSW disposal or processing facilities, enhanced timeous collection and improved MSW collection efficiency. The construction of MSW-WTS results from the need for remote and regional landfills which are large and require tracks of land and have to be located further away from urban population centres where there is no land for constructing such large landfills coupled with the human health concerns of having landfills near population centres emanating from flies, rodents, mosquitoes as well as stray animals $[2,18]$. Low tipping fees can be charged at large regional landfills due to their economies of scale which enable them to handle high MSW volumes from different sources under wider spatial scales thereby attracting more clients. Where MSW disposal and processing plants are over $15 \mathrm{~km}$ from MSW sources from which MSW is collected, there is a possibility of establishing WTS at strategic sites within an urban area to cut on MSW transportation costs. The general rule with regards to the siting of MSW disposal sites and processing facilities is that they have to be established distant away from the urban population centres due to their associated potential human health and environmental impacts. This makes the primary MSW collection vehicles to travel long distances from MSW sources to the disposal sites and processing facilities leading to increased duration of travelling to and from disposal and processing facilities, increased number of primary MSW collection vehicles and cost in the MSW collection system. The increased number of primary MSW collection vehicles emanates from increased MSW generation coupled with the increased duration the vehicles take to and from MSW disposal sites and processing facilities since primary waste collection vehicles are light weight carrying vehicles capable to navigate the streets collecting waste at sources a difficult undertaking using heavy vehicles. WTS therefore provide the necessary infrastructure or platform for the transfer of MSW from light weight carrying vehicles to heavy weight carrying vehicles commonly referred to as secondary waste carrying vehicles. This combination of low weight and heavy weight carrying vehicles in a MSW collection system brings about costs reduction compared to the use of primary waste collection vehicles alone.

Apart from waste transportation cost reduction, the consolidation of light waste weight or smaller waste volumes from light weight carrying vehicles into heavy weight carrying vehicles increases the effectiveness and efficiency of a waste collection system through the reduction of the time waste collection teams take transporting MSW between MSW sources and disposal and or processing facilities giving more time for waste collection [25]. Ultimately this reduces the number of light weight carrying vehicles subsequently reducing pollution, noise and traffic congestion within an urban centre. Considering the atleast $40 \%$ organic waste composition in MSW generated in Harare [12] and high temperatures for Harare which speeds up the decomposition of biodegradable waste, WTS provide mechanisms for frequent and timeous biodegradable MSW collection prior to its decomposition resultantly avoiding potential human health and environmental risks, odours etc as argued by [26]. The timeous or just in time MSW collection thus is enhanced by the increased collection frequency brought about by the WTS emanating from the reduced durations taken and distances travelled by primary waste collection vehicles collecting waste from sources to WTS.

MSW transportation is associated with the consumption of fuel by waste collection vehicles subsequently causing air pollution and other accompanying environmental and human health impacts. The Global Warming Potential (GWP) emanates from the 1004 
emission of greenhouse gas (GHG) from waste collection vehicles travelling to and from waste disposal and processing facilities as well as during waste collection at sources. Therefore, the associated reductions in times spent and distances travelled by primary waste collection vehicles or at source collection vehicles brought about by incorporating WTS in MSWM systems reduce the associated potential global warming impacts and other environmental impacts. This is so because WTS reduces the total distance MSW-CT vehicles travel resulting in reduced fuel consumption, GHG emissions and costs of maintaining MSW-CT vehicles.

The United Nations Environmental Program (UNEP) reported over ten thousand climate change induced disasters to have occurred and been witnessed, destroyed and killed property and millions respectively, affecting many more globally. MSW was cited by [27] amongst the primary contributors to the emissions of GHG that cause global warming or climate change that has led to these disasters. MSW derived GHG emissions significantly emanate from MSW-CT. Two hundred and fifty million tons of MSW were reported by [28] to have been processed in the United States of America, producing GHG emissions that accounted for over $8 \%$ of non-energy derived GHG emissions and $2 \%$ of total net GHG emissions. The projected increase in global MSW generation from 1.3 billion tons to 2.2 billion tons in 2011 and 2025 respectively $[1,28]$, has brought and anticipated to result in increased MSW-CT derived GHG emissions. Efforts towards reducing MSW derived GHG emissions require the design, development and implementation of technically feasible and sound, economically viable, environmentally sustainable and socially acceptable MSW-CT systems [29] that makes the reduction of carbon dioxide emission feasible [30]. In [31], the authors therefore, noted the appropriateness with regards to financial savings and environmental benefits include land use planning of incorporating WTS in the MSW-CT systems within developing nations.

WTS also ease the selection of new sites for waste disposal and processing by eliminating the overreliance on at source collection vehicles accessibility to the sites giving preferences and considerations to human health and environmental concerns. Therefore, WTS allows for waste disposal and processing facilities location further away from human settlements thereby reducing human health risks from disease causing vectors like mosquitoes, flies, stray animals, rodents and leachates. WTS further provide platforms for waste screening before final disposal, the needed flexibility to choose MSW treatment and disposal options as well as serving as citizen drop off station.

\subsection{Siting WTS}

The selection or identification of a suitable location of a WTS is a tedious and difficult process. Environmental and human health potential hazards need to be taken into consideration when assessing all potential WTS locations. Such factors include but not limited to potential nuisance, odours, noise from primary and secondary waste collection vehicles as well as WTS equipment, proximity and accessibility to sources with high waste throughput. A number of potential locations are identified first after which a comparative evaluation is undertaken to identify the best site that has minimum impacts with regards to some or all of the factors highlighted above. A number of studies have been conducted

www.astesi.com during the past twenty years using different approaches and considering different factors to identify the best WTS locations in different countries. The need for waste management cost minimisation as a factor for best WTS location was observed in most of the studies namely; [32]-[40] etc. In [37], the authors further observed other economic, environmental and social benefits of WTS incorporation and its suitable location in a waste management system that results in the simultaneous reduction of GHG emissions and resultant visual pollution apart from the reduced overall waste management costs in Tehran, Iran. In [34] and [40], the authors also noted revenue generation from waste processing facilities associated with WTS. For Harare therefore, MSWM costs and pollution reduction as well as revenue generation from MSW processing should be considered when deciding for the establishment and location of WTS. Thus, sustainability indicators for WTS in Harare will be based on cost effectiveness, reduction in water, land and water pollution, ability to accommodate the already at source collection vehicles being used by the ULAs, local expertise capable of designing, constructing and operating the WTS and energy efficiency.

\subsection{Economic viability of WTS}

As previously highlighted that WTS reduces the duration at source waste collection vehicles take collecting MSW and hence the reduction of primary MSW collection costs as well as the number of involved vehicles, economic viability of WTS is based on the breakeven point. This involves the comparison of WTS costs, hauling costs of primary or at source waste collection vehicles and secondary waste collection vehicles. Hauling costs have variable and fixed costs. Variable costs include fuel consumption, tyre, maintenance, depreciation, engine oil, and grease and waste collection crew wages. WTS costs encompass construction, operation and maintenance costs, calculated based on capacity basis with the distances between MSW final disposal and processing facilities and MSW sources being the only key consideration in determining WTS need. The following derivation by [41] identified the dependency and is used for assessing economic viability.

By having the following;

i. The hauling costs with primary or at source collection vehicles be a $\$ / \mathrm{ton} / \mathrm{km}$

ii. The hauling costs with secondary collection vehicles be $\mathrm{c} \$ / \mathrm{ton} / \mathrm{km}$

iii. The WTS costs be $b \$ /$ ton

iv. The distance between MSW sources and WTS be $\mathrm{x} k m$

v. The distance between WTS and MSW disposal and or processing facility be $\mathrm{ykm}$

vi. Total hauling costs with WTS using primary or at source collection vehicles and secondary collection vehicles be $\mathrm{TC}_{1}$ and without a WTS using only the primary or at source collection vehicles be $\mathrm{TC}_{2}$ respectively

Therefore;

$$
\begin{aligned}
& T C_{1}=a x+b+c y \\
& T C_{2}=a x+a y
\end{aligned}
$$


For WTS to be economically viable;

$$
T C_{1} \leq T C_{2}
$$

Thus,

$$
\begin{gathered}
a x+b+c y \leq a x+a y \\
y \geq \frac{b}{a-c}
\end{gathered}
$$

Therefore, the breakeven distance between WTS and MSW disposal or processing facilities is site specific and depends on a number of different input parameters.

\section{4. $L C A$ in $M S W M$}

Developments in the management of MSW has brought about the advent of the Integrated Municipal Solid Waste Management (IMSWM) model that entails combining socially acceptable, technically sound, economically feasible and environmentally sustainable MSW storage, collection and transportation, treatment and final disposal systems to manage MSW [42]. Such MSWM systems are complex to design and implement due to the difficulties associated with the need to optimize more than one variable hence the need for tradeoffs. LCA has come in handy as a computer based tool that can be applied during the design, development and implementation of such complex MSWM systems within the framework of the IMSWM model. LCA was described by [43] as a computer aided tool or decision support system that holistically quantifies estimates of potential environmental loads and or impacts of the entire life cycles of products and or processes. In [44], the authors described LCA further as a science-based method of assessing the environmental impacts of a system and or product though not being an entire scientific tool.

Three LCA methodologies have been described by [45] namely Social LCA (S-LCA), Environmental LCA (E-LCA) and Life Cycle Costing (LCC) based on the 3Ps - three-pillar approach towards sustainable development namely People, Planet, and Profit respectively. Despite the reported development of more integrated Life Cycle Sustainability Assessment (LCSA) approaches by [46] and [47], in [45] the authors noted the difficulties of combining the three methodologies due to overlapping issues during results interpretation thus it is advisable to undertake E-LCA, LCC and S-LCA separately. In [45], the authors however, reported the possibility of applying S-LCA individually or combined with E-LCA and/or LCC.

LCA application in informing decision making and policy formulation in MSWM systems design, development and implementation has been used since 1995 [48]. Its application in MSWM strategy development including decision making and policy formulation has expanded significantly during the past few years as a sustainability assessment tool that assists in solving the complexities and interdependencies of modern IMSWM systems [49]. In [50], the authors reported its potential in helping the designing of MSWM systems that reduce local pressures and associated MSWM costs, simultaneously considering the wider trade-offs and impacts of a MSWM system felt in other areas across a specific spatial scale. Spatial scale differences together with those differences with regards to MSW generation rates, composition and characteristics, sources of energy, available MSW treatment and disposal methods with their associated products and services renders LCA appropriate or suitable to aid MSWM strategy development, decision making and policy formulation $[51,52]$. It has emerged therefore as an appropriate and suitable holistic method with increasing wider application in MSWM strategy development, decision making and policy formulation [52, 53]. Several MSWM based LCA studies have therefore been carried out in the past with [54] having reviewed one hundred and fifty three studies carried out and published globally from 2013 to 2018, [55] analysed 91 studies carried out from 2006 to 2017 in Asian nations, [56] and [57] reviewed two hundred and twenty two studies they accessed including two hundred and seventeen from peer reviewed journal articles and fifteen public reports.

MSWM based LCA studies assesses different MSW management processes usually referred to as life cycle stages of MSW individually or a combination of processes within a MSWM system with regards to storage, collection, transportation or transfer, treatment and final disposal. These MSW life cycle stages includes the collection and transportation or transfer of MSW including WTS operations. For example, in [52], the authors incorporated WTS in their MSWM based LCA in Greece assuming that all the MSW generated is collected and transported to WTS prior to being sent to the different MSWM, treatment and disposal facilities. Other studies do not incorporate WTS and MSW-CT under the different scenarios arguing that the impacts will be the same under the different scenarios considering same functional unit. However, by considering the reducing effect that WTS have on the impacts from MSW-CT, it is wise to estimate the impacts associated with MSW-CT as it is likely to give an indication of its contribution to the overall MSWM scenario impacts. Higher contributions of MSW-CT will entail the need to redesign the collection and transportation system with the incorporation of WTS being a worthwhile consideration. Likewise MSWM based LCA studies were undertaken to inform possible least impactful MSWM systems that could be considered by decision makers and policy formulators for future implementation in and around Harare City, in Zimbabwe [15, 22, 58]. There is therefore need to assess the contribution of MSW-CT to the impacts of the overall MSWM options that were developed and assessed for their Life Cycle Impacts (LCI) to evaluate any need thereof of WTS considering their reducing effect on MSW-CT derived impacts.

\subsection{MSW-CT contribution to LCI of MSWM in Harare}

WTS incorporation in a waste management system brings about reductions in environmental or life cycle impacts. In [59], the authors observed a possible $16.8 \%$ average reduction in environmental or life cycle impacts when WTS are incorporated in a waste management system. MSWM based LCA studies were carried out to assess impacts of six developed MSWM scenarios that could be put for future implementation considerations in Harare. One of the MSW life cycle stages within the MSWM scenarios that was assessed for its impacts was the MSW-CT considering its contribution to Human Health Potential (HHP), Acidification Potential (AP), GWP or climate change and Eutrophication Potential (EP) of six developed MSWM scenarios for Harare City, Chitungwiza, Ruwa, Epworth and Norton. 
The 467,303 tons of MSW generated in Harare City, Chitungwiza, Ruwa, Epworth and Norton [12, 22, 24, 60] are indiscriminately collected and transported for their subsequent landfilling and incineration under MSWM options 1 and 2 respectively with the recovery of energy and landfill leachate, incineration bottom ash and flue gas treatment. Zimbabwe's road infrastructural needs will likely provide a ready market for incineration bottom ash use in road construction. 196,167 tons of source separated biodegradable MSW fraction is subjected to anaerobic digestion (AD) with the recovery of energy from produced biogas whilst the remainder amounting to 271,036 tons mixed bag non-biodegradable MSW fraction undergo incineration under MSWM option 3 with incinerator bottom ash and flue gas treatment. The only distinction under MSWM option 3 and 4 is the landfilling of the remaining 271,036 tons mixed bag nonbiodegradable MSW fraction associated with landfill leachate treatment and energy recovery. MSWM option 5 and 6 involve the same processes under MSWM options 3 and 4 respectively serve for the recovery of $20 \%$ of the 271,036 tons mixed bag nonbiodegradable MSW fraction that are recovered for recycling and reuse purposes being the sole difference.

Several LCA softwares exist in the market. SimaPro software and its embedded Ecoinvent database has been widely used for MSWM based LCA studies having been used by a significant majority of studies reviewed by [53]-[57] and [61]. SimaPro has been and is widely applied because it is generic in nature with universal application capabilities. It also possess a broad database with embedded features from environmental product declarations generation, carbon and water footprints provision as well as sustainability and multi-language interface reporting [55]. SimaPro is standardized which enables it to generate universal and reliable results. It is capable of analysing complex MSWM systems and is based on the Ecoinvent database that has a wide parametric coverage [62]. SimaPro gives MSWM scenarios with description of MSW streams rather than product terms [63] and can be used under spatial scales characterised by general lack of information on MSWM practices [52]. Therefore SimaPro 8.5.2 software and update852 together with the embedded Ecoinvent 3 database (2018) were used [64]. The reference flow of 467,300 tons of MSW generated per annum was used as the functional unit as having been applied in other studies [65-67]. Results are shown in Figure 3 and Tables 1 to 4.

\section{MSW Recycling Promotion}

The MSW generated in Harare City, Chitungwiza, Ruwa, Epworth and Norton is reportedly suitable for recycling and reuse with [12] and [68] having observed respectively atleast $75 \%$ and $90 \%$ reusability and recyclability potentials. The potential reusability and recyclability of the MSW has remained an untapped low hanging fruit that could address some of the MSWM challenges considering the $10 \%$ recycling reported by [8] and [24] shown in Figure 2a. WTS have largely been reported to provide platforms towards materials recovery and recycling promotion hence their design, construction and operation could significantly increase the MSW recycling and reuse figures to levels that could reduce or result in net zero HHP, AP, EP, and GWP observed by [22] for the MSWM options that could be earmarked for future implementation in Harare City and its surrounding urban population centres of Chitungwiza, Epworth, Ruwa and Norton.

WTS could be operated under a mixed bag MSW collection system or a source separation MSW collection system. Incorporating source separation and WTS operation apart from easing and enhancing MSW recycling, was observed that it brings along with it environmental benefits due to the reduced environmental impacts. In [52], the authors identified that combining WTS with a separation at source MSW collection system and the recycling of plastics, metals, paper and glass MSW fractions as well as biological treatment of biodegradable MSW fraction yielded the overall optimum results with regards to GWP, Human Toxicity, AP, EP, Ozone Layer Depletion, and Photochemical Ozone Creation Potentials under the CML 2001 Method and HHP, Ecosystems and Resources Damage under Ecoindicator 99 method. Interestingly, the Zimbabwe National Integrated Solid Waste Management Plan provides for source separation of MSW thus providing a solid basis and foundation for having WTS under a separation at source MSW-CT systems whose opportunities and challenges are extensively discussed in [14].

Though they are not regarded WTS in the strictest terms, Citizens Drop Off Points (CDOPs) or Centres (CDOCs) sometimes referred to as Citizens Convenient Centres (CCCs) together with Buy Back Centres (BBCs) can also be considered to compliment WTS in aiding recycling and addressing some of the MSWM challenges associated with increased amounts of waste being sent to landfills. CDOPs are facilities were residents dispose of their recyclable MSW materials. CDOPs provides specific recyclable MSW receptacles where citizens or residents come and deposit or dispose of their recyclable MSW. CDOPs demands a great deal of citizens effort, willingness and time to transfer their recyclable MSW hence the need for them to be located within a radius easily accessible to residents. BBCs are facilities where individuals and or businesses sell recyclable MSW materials for BBCs to either process or sell to recycling companies. They provide the much needed linkage between MSW generators and recyclers. Unlike at WTS where those who come to drop waste are supposed to pay tipping fees, at BBCs only appropriate recycles are to be dropped off with those bringing in the recyclable materials paid. However waste pickers can also get paid for delivering recyclable MSW to the Materials Recovery Facilities based WTS. BBCs and MRFs therefore provide a source of livelihoods for both formal and informal waste pickers. BBCs however, must be appropriately located for ease access to waste pickers after ascertaining the availability of reasonable recyclable MSW quantities. The price of recyclable materials determines the sustainability of BBCs whereas tipping fees largely determines the sustainability of WTS. Therefore WTS, CDOPs and BBCs can be considered for incorporation within future MSWM strategies that seek to reduce the human health and environmental impacts currently being experienced in Harare city and its surrounding urban centres. Their consideration for development and operation will aid the diversion of MSW from landfills through materials recycling. 

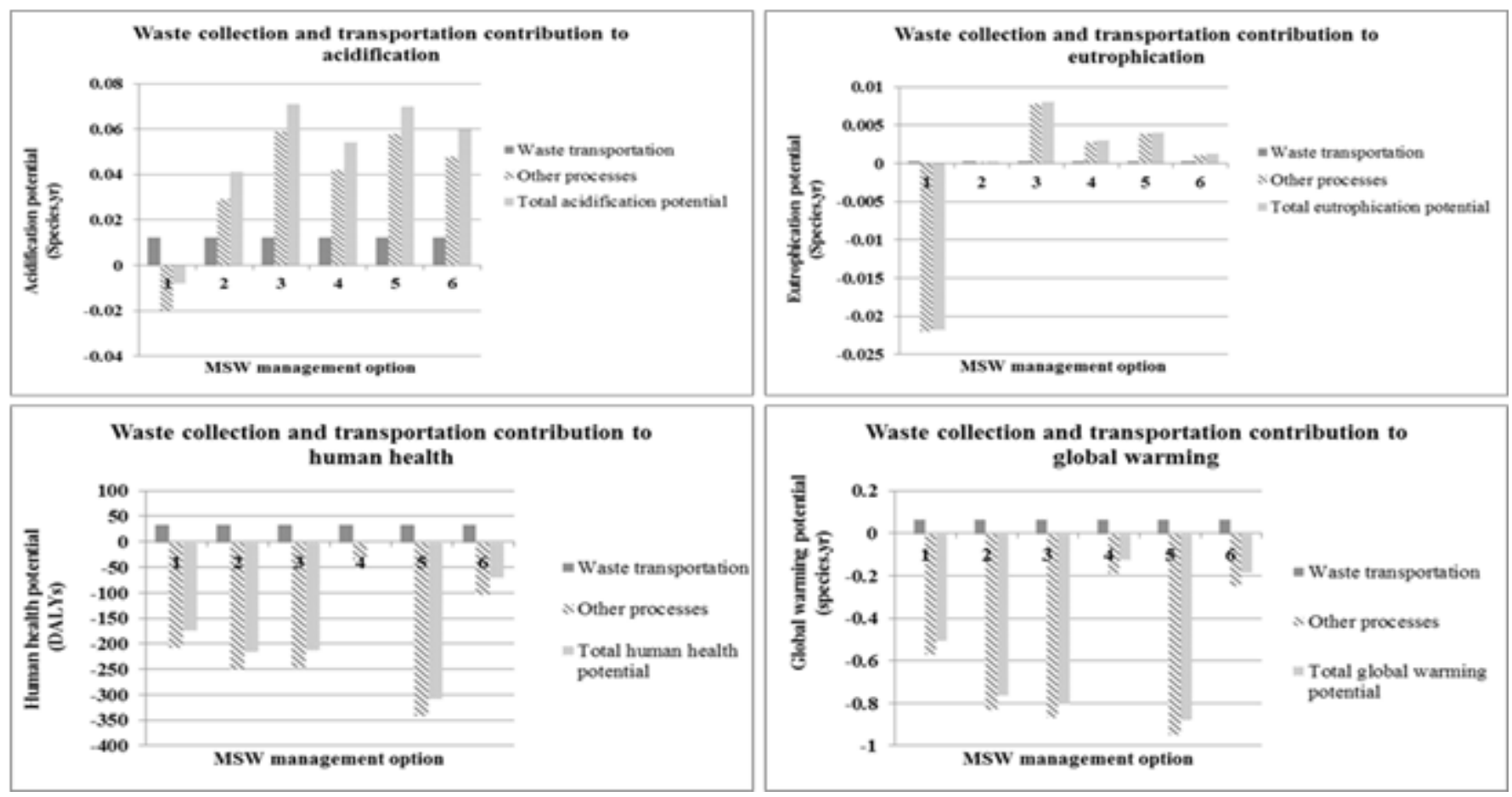

Figure 3: MSW-CT contribution to LCI

Table 1: MSW-CT contribution to AP (species.year)

\begin{tabular}{|l|c|c|c|c|c|c|}
\hline \multirow{2}{*}{ Process } & \multicolumn{6}{|c|}{ MSWM Option } \\
\cline { 2 - 7 } & $\mathbf{1}$ & $\mathbf{2}$ & $\mathbf{3}$ & $\mathbf{4}$ & $\mathbf{5}$ & $\mathbf{6}$ \\
\hline MSW-CT & 0.012 & 0.012 & 0.012 & 0.012 & 0.012 & 0.012 \\
\hline Other MSWM processes & -0.02 & 0.029 & 0.059 & 0.042 & 0.058 & 0.048 \\
\hline Total AP & $\mathbf{- 0 . 0 0 8}$ & $\mathbf{0 . 0 4 1}$ & $\mathbf{0 . 0 7 1}$ & $\mathbf{0 . 0 5 4}$ & $\mathbf{0 . 0 7 0}$ & $\mathbf{0 . 0 6 0}$ \\
\hline
\end{tabular}

Table 2: MSW-CT contribution to EP (species.year)

\begin{tabular}{|l|c|c|c|c|c|c|}
\hline \multirow{2}{*}{ Process } & \multicolumn{6}{|c|}{ MSWM Option } \\
\cline { 2 - 7 } & $\mathbf{1}$ & $\mathbf{2}$ & $\mathbf{3}$ & $\mathbf{4}$ & $\mathbf{5}$ & $\mathbf{6}$ \\
\hline MSW-CT & 0.0002 & 0.0002 & 0.0002 & 0.0002 & 0.0002 & 0.0002 \\
\hline Other MSWM processes & -0.0220 & 0.00001 & 0.0078 & 0.0028 & 0.0038 & 0.0010 \\
\hline Total EP & $\mathbf{- 0 . 0 2 1 8}$ & $\mathbf{0 . 0 0 0 2 1}$ & $\mathbf{0 . 0 0 8 0}$ & $\mathbf{0 . 0 0 3 0}$ & $\mathbf{0 . 0 0 4 0}$ & $\mathbf{0 . 0 0 1 2}$ \\
\hline
\end{tabular}

\section{Supporting Legislation and institutional framework}

The Environmental Management Act [Chapter 20:27] Subsection $1 \mathrm{~b}(\mathrm{ii})$ under Section 10 of the Act mandates or authorizes the Environmental Management Agency in Zimbabwe to regulate and monitor the recycling of waste among other MSWM including MSW-CT and disposal. The Director General, inspectors and other officers of the Agency are authorised to ensure through monitoring that waste is either recycled and or re-used whenever possible and disposed only in a responsible manner under Subsection (d) of Section 36 of the Act. Every waste generator is obliged to take appropriate measures essential for waste minimisation through recycling amongst other actions under subsection 3 of Section 70 of the Act. Statutory Instrument (SI) 10 of 2007 which authorizes ULAs to manage MSW provides for MSW recycling amongst the MSWM functions and demand every waste generator including ULAS to prepare annual waste management plans that provides for waste recycling wherever practicable in an environmentally safe form and manner amongst the specific goals provided under Subsection 1b(iii) of Section 13. Environmental Impact Assessments (EIAs) are required prior to the establishment of MSW recovery/recycling plants under $11 \mathrm{~b}$ of the First Schedule of the Act. This could bring challenges in 
attracting private players in establishing WTS, CDOPs and BBCs considering the bottlenecks and associated bureaucratic challenges associated with EIA approvals.

The Zimbabwe Waste Sector Low Emission Development Strategy (LEDS) for the Nationally Determined Contributions to its Paris Agreement differential obligations or responsibilities under the UNFCCC does not include MSW recycling despite the need to increase the MSW recycling levels provided for in the ZNISWMP and the Zimbabwe National Climate Change Response Strategy (ZNCCRS). This is a clear policy inconsistence that brings about challenges towards policy implementation. Though the ZNISWMP did not specifically provides for the construction of WTS, CDOPs and BBCs, amongst its strategic objectives is the need to develop infrastructure for waste management including waste recycling centres. Therefore it could be argued that the plan do provides for the development and operation of WTS, CDOPs and $\mathrm{BBCs}$ under the recycling centres considering the role they play to promote recycling as facilities for recycling. Goal 4 of the plan seeks to optimize resource recovery through the creation of an enabling environment for recovery; expansion of markets for recyclable MSW and forging partnerships in the recyclable waste value addition chain. It is evidently clear that a relatively fair legislative and institutional framework is available for recycling promotion and the establishment of recycling facilities. However specific provisions with regards to the siting, construction and operation of WTS, CDOPs and BBCs are absent. The other ingredient which is stakeholder involvement is at an undesirably low to support the construction and operation of CDOPs and BBCs based on the prevailing "We Dumb They Collect" attitude and general lack of willingness to pay for MSWM services provided by the ULAs amongst the residents.

\section{Results and Discussion}

The factors that support the need for WTS incorporation in a MSWM system identified from literature justifies the need for WTS to contribute to addressing the significant MSWM challenges currently prevailing in Harare City and the surrounding urban centres of Chitungwiza, Ruwa, Epworth and Norton. The increased population densities and major infrastructural developments coupled with their demand for residential and commercial land bring about increased competition for land leading to the unavailability of land for MSWM facilities especially landfills which require large pieces of land. In [2] and [18], the authors reported that landfill facilities provides favorable environment and conditions for flies, mosquitoes, rodents and mosquitoes together with stray animals to thrive. Therefore, apart from their demand for land which has numerous competing interests, landfill facilities are not desirable in the vicinity of Harare city and the surrounding urban centres which are already experiencing perennial and annual outbreaks of water borne diseases (cholera, dysentery, typhoid etc). This is so because siting landfills near these population centres will further these current human health and environmental impacts, hence landfill facilities to manage MSW generated in Harare City and the surrounding urban centres of Chitungwiza, Ruwa, Epworth and Norton must be sited further away from these population centres due to the already prevailing human health and environmental impacts coupled with the unavailability of affordable land for landfill facilities and other
IMSWM operations such as MSW incineration, pyrolysis, gasification and anaerobic digestion.

The location of MSW landfills further from the population centres entails an increased MSW-CT costs and by considering the high MSW-CT costs being reported for Harare and its dormitory urban centres, the incorporation of WTS in future MSWM systems pose to be an ideal strategy with the potential to bring significant MSW-CT costs reduction overally reducing the burden on the MSWM budget. However, quantitative assessments need to be carried out to determine the possible MSW-CT costs reductions that WTS will bring about. This will also entail the determination of the breakeven distance between MSW sources and the WTS that bring about effectiveness in MSW-CT cost. It has been reported that WTS lead to increased effectiveness and efficiency in MSW$\mathrm{CT}$ through the reduction of time spent by waste collection teams moving to and fro MSW disposal facilities availing more time to be spent on MSW collection [25]. This will likely reduce the likelihood of organic MSW fraction decomposition prior to its collection and associated diseases outbreaks. Reductions in fuel consumptions and accompanying GHG emissions as well as waste collection vehicles maintenance costs are anticipated from incorporating WTS in a MSWM system. The reduction in GHG emissions will contribute to the global and national efforts on GHG emission reduction targets hence these reductions will contribute to the Zimbabwe LEDs towards fulfilling its NDCs within the Paris Agreement on differential responsibilities framework. Certain waste fractions such as stumps, fuel tanks despite being empty or filled, furniture, explosives, hazardous waste, electrical appliances, explosives, dead animals, sludge, oils and liquids are not ideal for deposition or disposal at WTS. Fortunately MSW generated in Harare and its surrounding urban centres does not include such waste as defined in the SI of 2007 under the Environmental Management Act [Chapter 20:27]. This further supports and justifies the need to incorporate WTS in future MSWM systems for Harare City, Chitungwiza, Ruwa, Epworth and Norton.

Results from LCA study on the contribution of MSW-CT to the AP, GWP, HHP and EP of MSWM options for possible future implementation considerations are given in Tables 1 to 4 and Figure 3. Results show that MSW-CT bring significant contributions to the AP, GWP, HHP and EP under all the six MSWM options. MSW-CT contributes to increased AP, EP, GWP and HHP of 0.012 species.year, 0.0002 species.year, 0.065 species.year and 34 DALYs respectively under all the six MSWM options. It is interesting to note that GWP brought the highest impact with regards to species extinction rate (species.year), largely emanating from the GHG emissions that cause climate change derived from fuel combustion in MSW collection vehicles during MSW-CT. The positive contributions of MSW-CT to all the four impacts categories entails the need to redesign future MSW-CT systems that could bring reductions to these impacts with the incorporation of distantly located WTS from population centres in such future systems likely to be an economically viable, environmentally sustainable and socially acceptable option. However, incorporating WTS with the source separation of MSW was found to bring optimal environmental performance of a MSWM system hence the need to design future MSW-CT under a source separation system to ensure the derivation of maximum environmental benefits. Consequently, the ZNISWMP provides for the need for separation at source thus providing an enabling framework or background to operate WTS under a separation at source MSW-CT system. 
Table 3: MSW-CT contribution to GWP (species.year)

\begin{tabular}{|l|c|c|c|c|c|c|}
\hline \multirow{2}{*}{ Processes } & \multicolumn{7}{|c|}{ MSWM option } \\
\cline { 2 - 7 } & $\mathbf{1}$ & $\mathbf{2}$ & $\mathbf{3}$ & $\mathbf{4}$ & $\mathbf{5}$ & $\mathbf{6}$ \\
\hline MSW-CT & 0.065 & 0.065 & 0.065 & 0.065 & 0.065 & 0.065 \\
\hline Other processes & -0.57 & -0.83 & -0.867 & -0.187 & -0.947 & -0.247 \\
\hline Total GWP & $\mathbf{- 0 . 5 0 5}$ & $\mathbf{- 0 . 7 6 5}$ & $\mathbf{- 0 . 8 0 2}$ & $\mathbf{- 0 . 1 2 2}$ & $\mathbf{- 0 . 8 8 2}$ & $\mathbf{- 0 . 1 8 2}$ \\
\hline
\end{tabular}

Table 4: MSW-CT Contribution to HHP (DALYs)

\begin{tabular}{|l|c|c|c|c|c|c|}
\hline \multirow{2}{*}{ Process } & \multicolumn{6}{|c|}{ MSWM option } \\
\cline { 2 - 7 } & $\mathbf{1}$ & $\mathbf{2}$ & $\mathbf{3}$ & $\mathbf{4}$ & $\mathbf{5}$ & $\mathbf{6}$ \\
\hline MSW-CT & 34 & 34 & 34 & 34 & 34 & 34 \\
\hline Other processes & -208 & -250 & -246 & -34 & -342 & -104 \\
\hline Total HHP & $\mathbf{- 1 7 4}$ & $\mathbf{- 2 1 6}$ & $\mathbf{- 2 1 2}$ & $\mathbf{0}$ & $\mathbf{- 3 0 8}$ & $\mathbf{- 7 0}$ \\
\hline
\end{tabular}

WTS, CDOPs and BBCs enhance recycling and divert a significant amount of waste from final disposal sites mainly landfills. The recycling of recyclable MSW fraction has been found to bring about significant environmental benefits from a review of LCA studies by [53]-[57] and [61]. In [22], the authors also noted significant environmental benefits that materials recovery and recycling bring about when it was considered under the study to determine least impactful MSWM option for possible future implementation in Harare City and surrounding urban centres. Incorporating WTS, CDOPs and BBCs in future MSWM systems in Harare City will likely to come with significant environmental benefits contributing to the addressing of the prevailing MSWM challenges and the low recycling figures of below $10 \%$ reported by [8] and [24]. Several legislations and policy documents provides for the need for MSW recycling namely the Environmental Management Act [Chapter 20:27], SI 10 of 2007, ZNCCRS and the ZNISWMP. Since WTS, CDOPs and $\mathrm{BBCs}$ facilitates the promotion and increase of recycling, it is therefore evident that they have a strong footing for their development and operation in Zimbabwean urban centres. However caution need to be noted in that there are no specific provisions for their construction within these pieces of legislative and policy documents serve for the ZNISWMP which generally provides for the need to develop infrastructure for waste management including waste recycling centres amongst its numerous objectives. Such lack of clarity on specific legislative, policy and institutional arrangements with regards to WTS, CDOPs and BBCs does not provide the needed confidence and certainty to would be operators of such facilities. The need for EIAs prior to the construction and operation of such facilities like WTS as provided for under the First Schedule of the Environmental Management Act [Chapter 20:27] will also bring its own challenges. Worryingly despite the reported provisions for the need for MSW recycling in a number of legislative and policy documents as well as WTS recycling promotion and GHG emission reductions, the National LEDs towards NDCs fulfillment under the Paris Agreement did not incorporate recycling which could justify WTS operationalization. This policy inconsistence brings challenges for institutional prioritisation of key action plans as decision makers and policy formulators at ULA level will justify none recycling to such inconsistencies.

\section{Conclusion and Recommendations}

Study findings have largely shown the suitability of incorporating WTS in future MSWM systems for Harare City and its surrounding urban centres as they will contribute to reducing the current human health and environmental impacts currently characterizing these urban environments. WTS will bring about location of landfills and other MSWM facilities further away from population centers, increasing recycling, reducing MSW-CT costs and burden on the overall MSWM budget, increase in MSW-CT effectiveness and efficiency, reduction in MSW-CT derived GHG emissions and other environmental and human health impacts etc. Combining WTS with a source separation MSW-CT system brings about maximum environmental benefits of a MSWM system hence future MSWM systems for Harare City and surrounding urban centres must incorporate WTS under a separation at source MSWCT system. A sound background that could be used to justify WTS as well as CDOPs ad BBCs based on their potential to increase recycling is available based on the need to promote recycling as provided in the Environmental Management Act [Chapter 20:27], SI 10 of 2007, NCCRS and the ZNISWMP. However, there is need to strengthen the legislation with regards to the development and operationalization of WTS as well as CDOPs and BBCs because specific legislative, policy and institutional framework are absent. Such specific legislative framework complimented with a corresponding regulatory and institutional framework for the design, proper siting and location as well as operation of WTS together with CDOPs and BBCs is needed. This will increase their effectiveness and efficiency simultaneously reducing their associated negative human health and environmental impacts. Unfortunately, the absence of such an enabling legislative, 
regulatory and institutional framework could have contributed to the evident silence on WTS incorporation in the proposed MSWM interventions in the ZNISWMP. Source reduction of MSW, materials recovery and recycling must be encouraged to lower the amount (volume and weight) of MSW that is earmarked for collection and transportation to distantly located facilities which will lead to fewer and smaller WTS and preservation of land. WTS have the potential of acting as CDOPs or CCCs resulting in reduced amount of MSW that is illegally dumped. Despite the observed suitability of incorporating WTS in the MSWM systems for possible future implementation in Harare City and its surrounding urban centres, there is however, need for further studies that determine the breakeven distance and LCA studies that specifically assess the associated environmental loads of incorporating WTS within the likely future MSWM systems.

\section{Conflict of Interest}

The authors declare no conflict of interest.

\section{Acknowledgment}

Special thanks go to University of Johannesburg Postdoctoral fellowship that supported this study. The authors would like to thank the Life Cycle Initiative for the 2017 Life Cycle award in the form of SimaPro software that was used to carry out the LCIA.

\section{References}

[1] D. Hoornweg and P. Bhada-Tata, What a Waste : A Global Review of Solid Waste Management. Urban development series;knowledge papers no. 15. World Bank, 2012.

[2] V. Yadav, S. Karmakar, A. K. Dikshit, and S. Vanjari, "A feasibility study for the locations of waste transfer stations in urban centers: a case study on the city of Nashik, India," Journal of cleaner production, 126, 191-205, 2016, doi:10.1016/j.jclepro.2016.03.017.

[3] C. Y. Cheng and J. Urpelainen, "Who should take the garbage out? Public opinion on waste management in Dar es Salaam, Tanzania," Habitat International, 46, 111-118, 2015, doi:10.1016/j.habitatint.2014.11.001.

[4] UNDESA, World Urbanization Prospects: The 2018 Revision, United Nations Department of Economic and Social Affairs, 2018.

[5] Zimstat, 2012 Zimbabwe Census National Report, Zimbabwe National Statistics Agency, 2013.

[6] M. Sujauddin, S. M. S. Huda, and A. R. Hoque, "Household solid waste characteristics and management in Chittagong, Bangladesh," Waste management, 28(9), 1688-1695, 2008, doi:10.1016/j.wasman.2007.06.013.

[7] K. Ravindra, K. Kaur, and S. Mor, "System analysis of municipal solid waste management in Chandigarh and minimization practices for cleaner emissions," Journal of cleaner production, 89, 251-256, 2015, doi:10.1016/j.jclepro.2014.10.036.

[8] IES, A situational Analysis of Solid Waste Management in Zimbabwe's Urban Centres, Institute of Environmental Studies, University of Zimbabwe, 2013.

[9] EMA, Statutory Instrument (SI) 10 of 2007: Environmental Management (Hazardous Waste Management) Regulations, Environmental Management Agency, 2007.

[10] N. I. Sinthumule and S. H. Mkumbuzi, "Participation in community-based solid waste management in Nkulumane suburb, Bulawayo, Zimbabwe," Resources, 8(1), 30-46, 2019, doi:10.3390/resources 8010030 .

[11] R. G. Tsiko and S. Togarepi, "A situational analysis of waste management in Harare, Zimbabwe," Journal of American Science, 8(4), 692-706, 2012.

[12] L. Makarichi, R. Kan, W. Jutidamrongphan, and K. A. Techato, "Suitability of municipal solid waste in African cities for thermochemical waste-toenergy conversion: The case of Harare Metropolitan City, Zimbabwe," Waste Management \& Research, 37(1), 83-94, 2019, doi:10.1177/0734242X18804029.

[13] T. Nhubu, "A review of municipal solid waste data for Harare, Zimbabwe," in WASTES 2019, Lisbon, Portugal, 2019.
[14] T. Nhubu, E. Muzenda, C. Mbohwa, and B. Patel, "Opportunities and limitations for source separation of waste generated in Harare," in WASTES 2019, 2019.

[15] T. Nhubu, E. Muzenda, and C. Mbohwa, "Eutrophication impact potential of solid waste management options in Harare," in WASTES 2019, 2019.

[16] UN-HABITAT, Solid waste management in the world's cities, Nairobi, Kenya,United Nations Human Settlements Programme, 2010.

[17] U. Sonesson, "Modelling of waste collection: a general approach to calculate fuel consumption and time," Waste Management \& Research, 18(2), 115123, 2000, doi: $10.1177 / 0734242 X 0001800203$.

[18] B. E. Washburn, "Avian use of solid waste transfer stations," Landscape and Urban Planning, 104(3-4), 388-394, 2012, doi:10.1016/j.landurbplan.2011.11.014.

[19] M. D. Bovea, J. C. Powell, A. Gallardo, and S. F. Capuz-Rizo, "The role played by environmental factors in the integration of a transfer station in a municipal solid waste management system," Waste management, 27(4), 543553, 2007, doi:10.1016/j.wasman.2006.03.020.

[20] L. Zhen-shan, Y. Lie, Q. Xiao-Yan, and S. Yu-mei, "Municipal solid waste management in Beijing City," Waste management, 29(9), 2596-2599, 2009, doi:10.1016/j.wasman.2009.03.018.

[21] EPA, Waste transfer stations: A manual for decision-making, Solid Waste and Emergency Response, Environmental Protection Agency, 2002.

[22] T. Nhubu and E. Muzenda, "Determination of the Least Impactful Municipal Solid Waste Management Option in Harare, Zimbabwe," Processes, 7(11), 785, 2019, doi:10.3390/pr7110785.

[23] T. V. Ramachandra and S. Bachamanda, "Environmental audit of municipal solid waste management," International Journal of Environmental Technology and Management, 7(3-4), 369-391, 2007 , doi:10.1504/IJETM.2007.015152.

[24] EMA, Waste generation and management in Harare, Zimbabwe: Residential areas, commercial areas and schools, Environmental Management Agency, 2016.

[25] L. Cui, L. R. Chen, Y. P. Li, G. H. Huang, W. Li, and Y. L. Xie, "An intervalbased regret-analysis method for identifying long-term municipal solid waste management policy under uncertainty," Journal of environmental management, 92(6), 1484-1494, 2011, doi:10.1016/j.jenvman.2010.12.006.

[26] M. Sharholy, K. Ahmad, G. Mahmood, and R. Trivedi, "Municipal solid waste management in Indian cities: a review," Waste management, 28(2), 459-467, 2008, doi:10.1016/j.wasman.2007.02.008.

[27] S. Consonni, M. Giugliano, and M. Grosso, "Alternative strategies for energy recovery from municipal solid waste: Part B: Emission and cost estimates," Waste management, 25(2), 137-148, 2005, doi:10.1016/j.wasman.2004.09.006

[28] J. W. Levis, M. A. Barlaz, J. F. DeCarolis, and S. R. Ranjithan, "A generalized multistage optimization modeling framework for life cycle assessment-based integrated solid waste management," Environmental modelling \& software, 50, 51-65, 2013, doi:10.1016/j.envsoft.2013.08.007.

[29] C. A. Teixeira, C. Avelino, F. Ferreira, and I. Bentes, "Statistical analysis in MSW collection performance assessment," Waste management, 34(9), 1584-1594, 2014, doi:10.1016/j.wasman.2014.04.007.

[30] L. I. Cioca, L. Ivascu, E. C. Rada, V. Torretta, and G. Ionescu, "Sustainable development and technological impact on $\mathrm{CO} 2$ reducing conditions in Romania," Sustainability, 7(2), 1637-1650, 2015, doi:10.3390/su7021637.

[31] C. Mora, R. Manzini, M. Gamberi, and A. Cascini, "Environmental and economic assessment for the optimal configuration of a sustainable solid waste collection system: a 'kerbside'case study," Production planning \& control, 25(9), 737-761, 2014, doi:10.1080/09537287.2012.750386.

[32] V. Yadav, P. P. Kalbar, S. Karmakar, and A. K. Dikshit, "A two-stage multiattribute decision-making model for selecting appropriate locations of waste transfer stations in urban centres," Waste Management, 114(2), 80-88, 2020, doi:10.1016/j.wasman.2020.05.024.

[33] P. Rathore and S. P. Sarmah, "Modeling transfer station locations considering source separation of solid waste in urban centers: A case study of Bilaspur city, India," Journal of Cleaner Production, 211, 44-60, 2019, doi:10.1016/j.jclepro.2018.11.100.

[34] V. Yadav, S. Karmakar, A. K. Dikshit, and S. Vanjari, "A feasibility study for thelocations of waste transfer stations in urban centers : a case study on the city of Nashik, India," Journal of Cleaner Production, 126, 191- 205, 2016, doi:10.1016/j.jclepro.2016.03.017.

[35] H. A. Eiselt and V. Marianov, "A bi-objective model for the location of landfills for municipal solid waste," European Journal of Operational Research, 235(1), 187-194, 2014, doi:10.1016/j.ejor.2013.10.005.

[36] C. Chatzouridis and D. Komilis, "A methodology to optimally site and design municipal solid waste transfer stations using binary programming," 
Resources Conservation and Recycling, 60, 89-98, 2012, doi:10.1016/j.resconrec.2011.12.004.

[37] F. Habibi, E. Asadi, S. J. Sadjadi, and F. Barzinpour, "A multi-objective robustoptimization model for site-selection and capacity allocation of municipal solid waste facilities : a case study in Tehran," Journal of Cleaner Production, 166, 816-834, 2017, doi:10.1016/j.jclepro.2017.08.063.

[38] H. Asefi and S. Lim, "A novel multi-dimensional modeling approach to integrated municipal solid waste management," Journal of Cleaner Production, 166, 1131-1141, 2017, doi:10.1016/j.jclepro.2017.08.061.

[39] D. Komilis, "Conceptual modeling to optimize the haul and transfer of municipal solid waste," Waste Management, 28(11), 2355-2365, 2008, doi:10.1016/j.wasman.2007.11.004.

[40] M. Badran and S. El-Haggar, "Optimization of municipal solid waste management in Port Said - Egypt," Waste Management, 26(5), 534-545, 2006, doi:10.1016/j.wasman.2005.05.005.

[41] H. Phelps, G. Heinke, J. Jonker, E. Ouano, and C. Vandecasteele, Management of Solid Wastes. Technical Report. UNESCO, 1996.

[42] F. McDougall, P. R. White, M. Franke, and P. Hindle, Integrated solid waste management: a life cycle inventory. John Wiley \& Sons, 2008.

[43] G. Rebitzer, T. Ekvall, R. Frischknecht, D. Hunkelerd, G. Norrise, T. Rydberg, W. P. Schmidt, S. Suh, B. P. Weidemai, D.W.Pennington, "Life cycle assessment: Part 1: Framework, goal and scope definition, inventory analysis, and applications," Environment International, vol. 30(5), 701-720, 2004, doi:10.1016/j.envint.2003.11.005.

[44] J. R. Winkler and B. Bilitewski, "Comparative evaluation of life cycle assessment models for solid waste management," Waste Management, 27(8), 1021-1031, 2007, doi:10.1016/j.wasman.2007.02.023.

[45] UNEP, Guidelines for Social Life Cycle Assessment of Products and Organizations. United Nations Environment Programme, 2020.

[46] J. B. Guinée, R. Heijungs, G. Huppes, A. Zamagni, P. Masoni, R. Buonamici, T. Ekvall, T. Rydberg, "Life Cycle Assessment: Past, Present, and Future," Environmental Science and Technology, 45(1), 90-96, 2011, doi:10.1021/es101316v.

[47] T. Schaubroeck and B. Rugani, "A revision of what life cycle sustainability assessment should entail: Towards modeling the net impact on human wellbeing," Journal of Industrial Ecology, 21(6), 1464-1477, 2017, doi:10.1111/jiec.12653.

[48] L. P. Güereca, S. Gassó, J. M. Baldasano, and P. Jiménez-Guerrero, "Life cycle assessment of two biowaste management systems for Barcelona, Spain," Resources, Conservation and Recycling, 49(1), 32-48, 2006, doi:10.1016/j.resconrec.2006.03.009.

[49] G. A. Blengini, M. Fantoni, M. Busto, G. Genon, and C. Zanetti, "Participatory approach, acceptability and transparency of waste Management LCAs: Case studies of Torino and Cuneo" Waste Management, 32(9), 112-1721, 2012, doi:10.1016/j.wasman.2012.04.010.

[50] K. Koneczny and D. W. Pennington, "Life cycle thinking in waste management: Summary of European Commission's Malta 2005 workshop and pilot studies," Waste Management, 27(8), S92-S9, 2007, doi:10.1016/j.wasman.2007.02.020.

[51] M. R. Mendes, T. Aramaki, and K. Hanaki, "Comparison of the environmental impact of incineration and landfilling in Sao Paulo City as determined by LCA," Resources, Conservation and Recycling, 41(1), 47-63, 2004, doi:10.1016/j.resconrec.2003.08.003.

[52] G. Banias, M. Batsioula, C. Achillas, S. L. Patsios, K. N. Kontogiannopoulos, D. Bochtis, N. Moussiopoulos, "A Life Cycle Analysis Approach for the Evaluation of Municipal Solid Waste Management Practices: The Case Study of the Region of Central Macedonia, Greece," Sustainability, 12(19), 8221, 2020, doi:10.3390/su12198221.

[53] K. Abeliotis, "Life cycle assessment in municipal solid waste management, INTECH Open Access Publisher, 2011.

[54] H. Khandelwal, H. Dhar, A. K. Thalla, and S. Kumar, "Application of life cycle assessment in municipal solid waste management: A worldwide critical review," Journal of cleaner production, 209, 630-654, 2019, doi:10.1016/j.jclepro.2018.10.233.

[55] P. Yadav and S. R. Samadder, "A critical review of the life cycle assessment studies on solid waste management in Asian countries," Journal of cleaner production, 185, 492-515, 2018, doi:10.1016/j.jclepro.2018.02.298.

[56] A. Laurent, J. Clavreul, A. Bernstad, I. Bakas, M. Niero, E. Gentil, T. H. Christensen, M. Z. Hauschild, "Review of LCA studies of solid waste management systems-Part II: Methodological guidance for a better practice," Waste Management, 34(3), 589-606, 2014, doi:10.1016/j.wasman.2013.12.004.

[57] A. Laurent, I. Bakas, J. Clavreul, A. Bernstad, M. Niero, E. Gentil, M. Z. Hauschild, T. H. Christensen, "Review of LCA studies of solid waste management systems-Part I: Lessons learned and perspectives," Waste Management, 34(3), 573-588, 2014, doi:10.1016/j.wasman.2013.10.045.

[58] T. Nhubu, E. Muzenda, C. Mbohwa, and E. O. Agbenyeku, "Comparative assessment of compositing and anaerobic digestion of municipal biodegradable waste in Harare, Zimbabwe," Environmental Progress \& Sustainable Energy, 39(4), 2020, doi:10.1002/ep.13376.

[59] M. D. Bovea, J. C. Powell, A. Gallardo, and S. F. Capuz-Rizo, "The role played by environmental factors in the integration of a transfer station in a municipal solid waste management system," Waste Management, 27(4), 545-553, 2007, doi:10.1016/j.wasman.2006.03.020.

[60] EMA, Zimbabwe's integrated solid waste management plan, Environmenntal Management Agency, 2014

[61] J. Cleary, "Life cycle assessments of municipal solid waste management systems: A comparative analysis of selected peer-reviewed literature," Environment international, 35(8), 1256-1266, 2009, doi:10.1016/j.envint.2009.07.009.

[62] E. Moreno Ruiz, T. Lévová, J. Reinhard, L. Valsasina, G. Bourgault, and G. Wernet, Documentation of changes implemented in ecoinvent database v3.3, Ecoinvent, 2016.

[63] A. Vidalis, D. Malamis, K. Moustakas, K. Valta, D. Bolzonella, P. Grammelis, M. Loizidou., Development and implementation of a demonstration system on Integrated Solid Waste Management for Tinos in line with the Waste Framework Directive., Municipality of Tinos, 2011.

[64] E. Moreno Ruiz, L. Valsasina, F. Brunner, A. Symeonidis, D. FitzGerald, K. Treyer, G. Bourgault, G. Wernet, "Documentation of changes implemented in ecoinvent database v3.5," Ecoinvent, 2018.

[65] Y. Fernández-Nava, R. J.D, J. Rodríguez-Iglesias, L. Castrillón, and E. Marañón, "Life Cycle Assessment (LCA) of different municipal solid waste management options: A case study of Asturias (Spain)," Journal of Cleaner Production, 81, 178-189, 2014, doi:10.1016/j.jclepro.2014.06.008.

[66] P. Beigl and S. Salhofer, "Comparison of ecological effects and costs of communal waste management systems," Resources, Conservation and Recycling, 41(2), 83-102, 2004, doi:10.1016/j.resconrec.2003.08.007.

[67] F. Cherubini, S. Bargigli, and S. Ulgiati, "Life cycle assessment (LCA) of waste management strategies: Landfilling, sorting plant and incineration," Energy, 34(12), 2116-2123, 2009, doi:10.1016/j.energy.2008.08.023.

[68] D. Tirivanhu and S. Feresu, A Situational Analysis of Solid Waste Management in Zimbabwe's Urban Centres,: Institute of Environment Studies-University of Zimbabwe, 2013. 